\title{
Bioactive substance contents and antioxidant capacity of raw and blanched vegetables.
}

\begin{abstract}
Five commonly consumed vegetables in Malaysia namely, four-angled bean (Psophocarpus tetragonolobus D.C.), French bean (Phaseolus vulgaris L.), long bean (Vigna sesquipedalis L.), snow pea (Pisum sativum var. macrocarpon L.) and snap pea (Pisum sativum) were blanched in boiling water for $10 \mathrm{~min}$. The contents of total phenolics, ascorbic acid and $\beta$ carotene, and the antioxidant capacity as typified by $\beta$-carotene and free radical scavenging activity (DPPH) assays were determined for the raw and blanched vegetables. The study revealed that blanching caused a significant $(\mathrm{p}<0.05)$ increase in $\beta$-carotene content [fresh $(389-539 \mu \mathrm{g} / 100 \mathrm{~g})$, blanched $(510-818 \mu \mathrm{g} / 100 \mathrm{~g})]$, except in snow pea. Conversely, there was a significant $(\mathrm{p}<0.05)$ decrease in ascorbic acid content [fresh $(1.2-7.8 \mathrm{mg} / 100 \mathrm{~g})$, blanched (0.67-3.8 mg/100 g)]. After blanching, the total phenolic content and antioxidant activity either decreased or increased depending on the type of vegetables. The total phenolic content was positively correlated with the antioxidant activity of the studied vegetables to some extent, but not with ascorbic acid or $\beta$-carotene.
\end{abstract}

Keyword: Antioxidant activity; Blanching; Phenolic; Vegetables 